\title{
Solar Power Plant Generation Short-Term Forecasting Model
}

\author{
Stanislav Eroshenko, Elena Kochneva, Pavel Kruchkov and Aleksandra Khalyasmaa \\ Automated Electrical Systems Department, Ural Federal University named after the first President of Russia B.N. Yeltsin, 19, Mira St., \\ Yekaterinburg, Russia
}

\begin{abstract}
Recently, renewable generation plays an increasingly important role in the energy balance. Solar energy is developing at a rapid pace, while the solar power plants output depends on weather conditions. Solar power plant output short-term forecasting is an urgent issue. The future electricity generation qualitative forecasts allow electricity producers and network operators to actively manage the variable capacity of solar power plants, and thereby to optimally integrate the solar resources into the country's overall power system. The article presents one of the possible approaches to the solution of the short-term forecasting problem of a solar power plant output.
\end{abstract}

\section{Introduction}

The solar power plants in the power system leads to the emergence of an additional uncertainty source, in addition to the load behavior. This uncertainty implements to the calculating the balance of consumption and generation in the power system. The balance of the produced and consumed electric power is necessary both for maintaining the frequency in the power system and for ensuring the economical operation of energy system other generating units, as well as the possibility of trading in the electricity and capacity market. A high percentage of the solar power plants installed capacity in the energy system will inevitably lead to an increase in the influence of the uncertainty factor of the solar plant power output on the electric grid operation. The reserve created to cover this uncertainty should be as small as possible to maximize the benefits of the solar power plants deployment.

According to the Russian Federation Government Resolution №449 “About using the renewable energy sources stimulation mechanism in wholesale and retail energy markets" taken on 28 may 2013 there is competitive selection of the investment projects for the generating facilities based on the renewable energy sources using construction. These competitive selections are held 4 years ahead for solar power plants. The results of selections held in 2013-2014, 76 objects with total capacity $1081 \mathrm{MW}$ have been selected. It is expected the selections in 2017-2018 will result in the solar power plants installed capacity increasing and covering the wide range of regions.

The solar energy market growth dynamics is characterized by the total volumes of installed capacities introduced and planned for commissioning. According to the list of renewable energy projects which were chosen during the competitive selection in 2017, 26 solar generating facilities are planned for commission in the period from 2020 to 2022 in unified energy system of Russia. The total installed capacity of these facilities is more than 500 MW [1-3]. The objects construction geography covers the whole southern part of the Russia territory. The single object installed capacity is in the range from 15 to $45 \mathrm{MW}$.

Thus, nowadays the solar power plants are independent participants of the wholesale electricity market and consequently can participate in competitive procedures. Thus, the function of solar power plant generation short-term forecast is required for trading on the day-ahead market. In turn, this function is a complex multicriteria task that is based on meteorological and climatic data, generating facility state data and the adjustment electrical network topological and mode data.

Taking into account the solar generation development intensity as well as the current market needs engineering company "ProSoft Systems" Ltd together with Ural Federal University named after the first President of Russia B.N. Yeltsin carried out the development and implementation of a short-term forecasting system for the electricity generation in photovoltaic plants in the framework of research and development work.

\section{Initial data}

Solar power plants generation short-term forecast is carried out on the "day ahead" interval for the purpose of ensuring the participation of photovoltaic generation in electricity markets commercial procedures and also on the 2-7-day perspective in order to solve medium-urgent object generation planning and power plant equipment maintenance and repair planning. 
Initial data for solar radiation energy flux density forecast at the ground surface falling on a horizontal surface forecast

\begin{tabular}{|c|}
\hline Geographical coordinates \\
\hline Latitude, [degree] \\
\hline Longitude, [degree] \\
\hline Local time \\
\hline Daylight saving time, [h] \\
\hline Estimated time interval \\
\hline Date (number of day in the year), [units] \\
\hline Weather data \\
\hline Solar radiation energy flux density on a horizontal \\
surface, [W/m ${ }^{2}$ ] \\
Cloud cover, [\%] \\
\hline Constants \\
\hline recommended retrospective depth is 14 days \\
\hline Solar constant, [W/m ${ }^{2}$ ] \\
\hline
\end{tabular}

(actual measurements) (actual measurements or weather provider data)

Fig 1. Initial data for the forecast first stage

The short-term forecasting function is implemented into the software package Energosfera 8.0 produced by "ProSoft Systems" Ltd. "Energosfera 8.0" is designed for automated systems of fiscal and technical metering for various types of energy resources (electricity, heat, water, steam, gas, etc.) building [4]. Solar plant accounting and monitoring devices automated data collection, data storage, primary data processing and information presenting to the software product user in the reports, graphs, tables and logs form is provided.

The following main data sources are used in the automated meter reading system Energosfera 8.0 for the correct short-term forecasting module operation:

- Horizontally mounted pyranometer for measuring the total energy flux density of solar radiation, $\left[\mathrm{kW} / \mathrm{m}^{2}\right]$;

- Online meteorological forecast data for solar power plant geographical coordinates [cloudiness, [\%]; description of meteorological conditions and events);

- Data from local weather station installed on the solar plant territory (wind speed, $[\mathrm{m} / \mathrm{s}]$; wind direction, [degrees]; air temperature, $\left[{ }^{\circ} \mathrm{C}\right]$; air humidity $\left.[\%]\right)$.

\section{Solar energy plant generation "a day ahead" forecast}

The algorithm for calculating the short-term forecast is practically implemented in three stages [5-7]:

1. Calculation of the solar radiation energy flux density forecast at the ground surface falling on a horizontal surface, $\left[\mathrm{kW} / \mathrm{m}^{2}\right]$.

2. Calculation of the energy solar radiation flux density at the ground surface incident on the solar panel inclined plane, $\left[\mathrm{kW} / \mathrm{m}^{2}\right]$.
3. Calculation of the hourly solar power plant output based on the current data on the state of plant generating equipment, [kWh].

Measurement data obtained from the monitoring systems established in the solar plant territory, the weather forecast data for the present day and calculated values determining the sunls movement nature are used for the solar radiation energy flux density forecast at a horizontal surface. Figure 1 presents the initial variables for the forecast first stage.

Solar radiation flux density change estimation when passing through the Earth's atmosphere is carried out using the normalized parameter called transparency coefficient. This coefficient takes into account the effects of such factors as the absorption of solar radiation by ozone, air molecules, water vapor, and cloud cover. The parameter "cloudness" in percentage terms is the most significant among the metrological forecast factors from the point of view of solar power plant generation forecast.

Meteorological condition short-term forecasting in the territory of Russian Federation is carried out in accordance with the current governing documents. For example, according to the national guidelines in the firld of meteorology the cloudness forecast should correspond to the 8-point scale (step 0,125 pu) [7]. However according to international standards the scale for the same variable should be divided into 10 points (step $0,100 \mathrm{pu}$ ). In a number of cases, a quantitative estimate of the cloudiness in \% is not presented, and a verbal description of weather conditions and events such as "fog", "cloudy", "cloudy with clearings," etc. is provided. As part of the software package Energosfera 8.0, an algorithm of recalculating the weather conditions and events in the corresponding values of cloudiness in percent is implemented. 
Calculation of solar radiation energy flux density at the surface of the earth on a horizontal surface

\begin{tabular}{|c|}
\hline Current values calculation \\
\hline Flux density of solar radiation reaching the earth, $\left[\mathrm{W} / \mathrm{m}^{2}\right]$ \\
\hline Solar declination angle, [degree] \\
\hline Solar time (including dawn, sunset, noon), [h] \\
\hline Hour angle, [degree] \\
\hline Cosine of zenith angle \\
\hline Angular altitude of the sun, [degree] \\
\hline Mean values calculation \\
\hline Average hourly value of the angular sun height, [degree] \\
\hline Average flux density of solar radiation at the boundary of the \\
atmosphere, [W/m2] \\
\hline Actual cloudiness value \\
\hline Average actual solar radiation energy flux density, [W/m²] \\
\hline \\
\hline \\
\hline
\end{tabular}

Flux density of solar radiation on the basis of the cloud cover forecast, $\left[\mathrm{W} / \mathrm{m}^{2}\right]$
2.

Figure 2. Block diagram of solar radiation flux density near the earth surface, falling on the horizontal plane calculation.

The transparency coefficient change is of a random nature, while the individual characteristics of the solar power plant location area have a great influence. Identification of the transparency coefficient statistical dependence on key characteristics is carried out using the multiple regression model. The block diagram of the program forecasting module "a day ahead" of the solar radiation flux density near the earth surface, falling on the horizontal plane, is presented in Figure 2.

After obtaining the required value of the solar radiation flux density according to the methodology presented above, a forecast is made for the solar power plant electricity generation. The procedure consists of three stages.

A. Determination of the photovoltaic panels direct current output power

The design power of one photovoltaic panel is determined by the equation [8-9]:

$$
P_{P V}=Y_{P V} f_{P V}\left(\frac{\bar{G}_{T}}{\bar{G}_{T, S T C}}\right)\left[1+\alpha_{p}\left(\bar{T}_{c}-T_{c, S T C}\right)\right],
$$

where $P_{P V}$ is power of one photovoltaic panel, [W]; $Y_{P V}$ is rated photovoltaic panel power at standard conditions (nameplate value), $[\mathrm{W}] ; f_{P V}$ is reduction coefficient of the overall panel efficiency as a result of degradation of photoelectric modules, [pu]; $\bar{G}_{T, S T C}$ is the solar radiation energy flux density under standard conditions, is assumed to be $1000 \mathrm{~W} / \mathrm{m}^{2} ; \alpha_{p}$ is the temperature coefficient of power (passport value), $\left[\% /{ }^{\circ} \mathrm{C}\right] ; \bar{T}_{c}$ is photovoltaic panel temperature, $\left[{ }^{\circ} \mathrm{C}\right]$; $T_{c, S T C}$ is photovoltaic panel temperature under standard conditions, is assumed to be $25^{\circ} \mathrm{C}$.

The presented model of power calculation, produced by a single photovoltaic panel, is universal for all types of crystalline photocells and photocells used on the basis of amorphous silicon and allows to take into account 
external conditions affecting the efficiency of panel production, and also take into account the degradation of the panel in the process operation.

B. Determination of the inverters output power

Semiconductor devices that provide power to the AC network can be also highlighted as part of the main solar power plant equipment. The used inverter model allows us to take into account the losses that occur during the conversion of a direct current into a variable one [10]:

$$
P_{a c}=\frac{P_{a c_{0}}\left(P_{d c}-P_{s_{0}}\right)}{P_{d c_{0}}-P_{s_{0}}},
$$

where $P_{a c}$ is output power on the $\mathrm{AC}$ side of the inverter, $[\mathrm{W}] ; P_{a c_{0}}$ is rated power on the AC side of the inverter (passport characteristic), $[\mathrm{W}] ; P_{d c}$ is power generated at the DC side, $[\mathrm{W}] ; P_{d c_{0}}$ is rated power on the DC side of the inverter (passport characteristic), [W]; $P_{s_{0}}$ is power consumption of the inverter (passport characteristic), [W].

C. Definition of solar power plant electricity generation

Determination of solar power plant electricity generation hourly value will be presented in further papers. The main influence on the result at this calculation stage is rendered by the generating facility electrical connection scheme, as well as the composition of the main equipment i.e. the types and number of photovoltaic panels, the types and number of inverters/converters, the equipment of the substation distribution device.

\section{Conclusion}

The developed short-term forecasting system is based on the physical model of solar radiation propagation in the Earth's atmosphere and allows to fulfill a short-term forecast of solar power generation based on the weather forecast data provided by the meteorological provider and a retrospective measurement of solar radiation flux density obtained from meteorological sensors installed on the territory of solar power plant.

A technique for short-term forecasting of the solar power plant is proposed. Taking into account the volume of the forecast information, a physical model is used to determine the averaged solar radiation entering the unit area of the horizontal surface of the Earth. The subsequent accounting of the geometric location of solar panels at the station, the description of the model of solar panels, converters, inverters, as well as the passport data of the substation equipment, will allow to determine the generation of a solar power station for the forecasted weather conditions. Since the physical model uses the meteorological forecast with hourly averaging as its input, its accuracy is equivalent to the accuracy of the forecast itself.

\section{References}

1. List of renewable energy projects selected according to the results of competitive selection in accordance with the Registry of selection of investment projects for construction of generating facilities operating on the basis of renewable energy sources/ Association of noncommercial partnership "Market Council". URL: https://www.atsenergo.ru/vie/proresults

2. William Glassley, Jan Kleissl. Current state of the art in solar forecasting. California renewable energy collaborative final report. (2013)

3. Utility-Scale Solar Photovoltaic Power Plants^ A Project Developer's Guide. International finance company. (2015)

4. Software package Energosfera. ProSoft Systems Ltd. URL: http://www.prosoftsystems.ru/ catalog/show/programmnyj-kompleks-jenergosfera1

5. Mohamed Abuella, Badrul Chowdhury. Solar Power Probabilistic nForecasting by Using Multiple Linear Regression Analysis. Department of Electrical and Computer Engineering, University of North Carolina, USA. (2015)

6. D.A. Snegirev, R.T. Valiev, S.A. Eroshenko, A.I. Khalyasmaa. Functional assessment system of solar power plant energy production. Proceedings of the $8^{\text {th }}$ International Conference on Energy and Environment (CEIM). Pp 397-353, (2017).

7. D.A. Snegirev, R.T. Valiev, S.A. Eroshenko, A.I. Khalyasmaa. Algorithmic realization of short-term solar power plant output forecasting. Proceedings of the II International Conference on Control in tecgnical systems (CTS'2017). Pp 228-231. (2017).

8. Guidance Document 52.27.724-2009 «Manual on Short-Term Weather Forecasts of General Purpose» / URL: http://docs.cntd.ru/document/437152648

9. Chiou-Jye Huang, Mao-Ting Huang, and ChungCheng Chen. A Novel Power Output Model for Photovoltaic Systems. International Journal of Smart Grid and Clean Energy. - № 2. - Pp 139-147. (2013)

10. D.L. King, S. Gonzalez, G. M. Galbraith and W. E. Boyson. Performance Model for Grid-Connected Photovoltaic Inverters. Albuquerque, NM, Sandia National Laboratories. 47 p. (2007).

\section{Acknowledgements}

The work was supported by Act 211 Government of the Russian Federation, contract № 02.A03.21.0006. 